\title{
PEMANFAATAN SLIDE MASTER POWER POINT UNTUK PEMBELAJARAN KIMIA PADA MATERI PENERAPAN LAJU REAKSI
}

\author{
SONNY ROHIMAT \\ SMA Negeri 6 Kota Serang \\ Email: albaregbegi@gmail.com
}

\begin{abstract}
ABSTRAK
Mata pelajaran kimia merupakan salah satu mata pelajaran yang tidak disukai oleh banyak peserta didik karena dirasa membosankan, sulit, dan menakutkan. Salah satu cara yang dapat menjadikan pembelajaran lebih jelas, menarik, interaktif, dan efisien adalah penggunaan media pembelajaran yang tepat. Salah satu pembelajaran berbasis komputer yang dapat digunakan sebagai media pembelajaran yang dapat mengakomodasi kecerdasan verbal, audio, maupun visual peserta didik adalah aplikasi power point dengan memanfaatkan fitur slide master. Penelitian dilakukan secara kualitatif dengan menggunakan metode deskriptif di SMA Negeri 6 Kota Serang pada kelas XI MIPA 4 tahun pelajaran 2019/2020 semester ganjil. Penelitian ini terdiri dari dua tahap, yaitu pembuatan media pembelajaran interaktif menggunakan master slide pada aplikasi Microsoft Power Point dan pembelajaran kimia memanfaatkan media pembelajaran tersebut dengan menggunakan model discovery learning. Media pembelajaran dengan memanfaatkan fitur slide master pada aplikasi Microsoft Power Point bisa dibuat untuk materi Penerapan Laju Reaksi. Hal ini didukung dengan model discovery learning yang mendorong peserta didik melakukan penemuan secara kolaboratif.
\end{abstract}

Kata Kunci : Media Pembelajaran, Kimia, Metode Pembelajaran.

\section{PENDAHULUAN}

Mata pelajaran kimia merupakan salah satu mata pelajaran yang tidak disukai oleh banyak peserta didik. Peserta didik merasa bahwa kimia merupakan mata pelajaran yang membosankan, sulit (Anisa \& Yuliyanto, 2017) tidak menarik, menakutkan, bahkan dianggap angker (Inayah \& Astuti, 2017. Hal ini dikarenakan peserta didik merasa bahwa dalam pelajaran kimia banyak hafalan dan hitungan. Apalagi banyak guru melakukan pembelajaran secara monoton di mana guru menjelaskan materi, peserta didik mendengarkan kemudian mengerjakan latihan soal pada buku (Anisa \& Yuliyanto, 2017). Kondisi seperti ini tentu saja tidak baik karena dapat menjadikan peserta didik merasa malas dalam mengikuti pembelajaran, mengantuk, bahkan merasa tidak nyaman (Pengestika, Wijayanti, \& Widodo, 2017).

Salah satu faktor yang dapat membantu guru dalam melaksanakan pembelajaran adalah media pembelajaran. Media pembelajaran dapat membantu siswa dalam memahami materi yang disampaikan serta memperkaya khasanah pembelajaran (Anisa \& Yuliyanto, 2017). Selain itu, media juga bisa membuat pembelajaran menjadi lebih jelas, menarik, interaktif, dan efisien (Amanah, 2016). Pada akhirnya, media pembelajaran ini dapat mempengaruhi hasil belajar siswa, baik pada ranah pengetahuan, keterampilan, mapun sikap (Amrina et al, 2019).

Penggunaan media pembelajaran pada mata pelajaran kimia di SMA Negeri 6 Kota Serang belum dilakukan dengan optimal. Pada umumnya guru hanya menggunakan media pembelajaran berupa papan tulis dan alat-alat praktikum di laboratorium. Padahal sarana dan prasarana di sekolah sangat memungkinkan untuk pemanfaatan media pembelajaran yang lebih bervariasi, misalnya menggunakan media pembelajaran berbasis komputer. Sarana pendukung seperti laptop, LCD proyektor, dan jaringan listrik di sekolah sudah memadai.

Berdasarkan kondisi tersebut maka diperlukan upaya untuk memperbaiki pembelajaran kimia melalui pengembangan media pembelajaran berbasis komputer. Salah satu aplikasi yang banyak digunakan untuk membuat media pembelajaran berbasis komputer yang relatif mudah adalah Microsoft Power Point. Media pembelajaran ini dapat mengakomodasi 


\section{STRATEGY : Jurnal Inovasi Strategi dan Model Pembelajaran Vol 1. No 1. Juli Tahun 2021 e-ISSN : 2798-5466 P-ISSN : 2798-5725}

beberapa kecerdasasan peserta didik seperti kecerdasan verbal, audio, maupun visual (Surachman, 2016). Agar lebih menarik dan interaktif, pembuatan media pembelajaran Microsoft Power Point dapat dilengkapi dengan pemanfaatan fitur Slide Master (Amrina et al, 2019).

Agar pemanfaatan media pembelajaran lebih efektif maka pembelajaran yang dilakukan harus menggunakan model pembelajaran yang sesuai. Salah satu model pembelajaran yang disarankan dalam kurikulum 2013 adalah model discovery learning. Model pembelajaran ini terdiri dari enam sintaks (tahapan kegiatan) yaitu pemberian rangsangan, identifikasi masalah, pengumpulan data, pengolahan data, pembuktian, dan penarikan kesimpulan (Devi, 2016). Model dan media pembelajaran ini juga bisa digunakan dalam pembelajaran kimia pada materi Penerapan Laju Reaksi. Materi ini merupakan salah satu materi pada Kompetensi Dasar (KD) 4.6. yaitu menyajikan hasil penelusuran informasi cara-cara pengaturan dan penyimpanan bahan untuk mencegah perubahan fisika dan kimia yang tak terkendali (Sutresna, Sholehudin, \& Herlina, 2016)

\section{METODE PENELITIAN}

Penelitian yang dilakukan merupakan penelitian kualitatif dengan menggunakan metode deskriptif. Penelitian kualitatif merupakan jenis penelitian dengan desain yang umum dan fleksibel, sampel yang kecil dan tidak representatif (Siyoto \& Sodiq, 2015), mementingkan proses, menjadikan peneliti sebagai instrumen penelitian, serta hasilnya berupa penemuan yang tidak dicapai menggunakan statistik (Sidiq \& Choiri, 2019). Penelitian dilakukan di SMA Negeri 6 Kota Serang pada kelas XI MIPA 4 tahun pelajaran 2019/2020 semester ganjil. Jumlah peserta didik pada kelas tersebut adalah 36 orang. Waktu penelitian dilaksanakan pada bulan Oktober 2019 jam pelajaran kimia pada materi Penerapan Laju Reaksi. Materi ini merupakan bagian dari KD 4.6. yaitu menyajikan hasil penelusuran informasi cara-cara pengaturan dan penyimpanan bahan untuk mencegah perubahan fisika dan kimia yang tak terkendali (Sutresna, Sholehudin, \& Herlina, 2016).

Penelitian ini terdiri dari dua tahap, yaitu pembuatan media pembelajaran interaktif menggunakan master slide pada aplikasi Microsoft Power Point dan pembelajaran kimia dengan memanfaatkan media pembelajaran tersebut. Kegiatan yang dilakukan pada tahap pembuatan media pembelajaran adalah membuat desain media pembelajaran serta pembuatan media pembelajaran menggunakan slide master pada aplikasi Microsoft Power Point. Pada tahap selanjutnya, media tersebut digunakan pada pembelajaran kimia dengan menggunakan model discovery learning.

\section{HASIL DAN PEMBAHASAN}

\section{Hasil}

Tahap pertama yang dilakukan pada penelitian ini adalah pembuatan media pembelajaran interaktif. Tahap pertama ini diawali dengan pembuatan desain atau rancangan media pembelajaran yang akan digunakan. Desain media pembelajaran disajikan pada Gambar 1. 


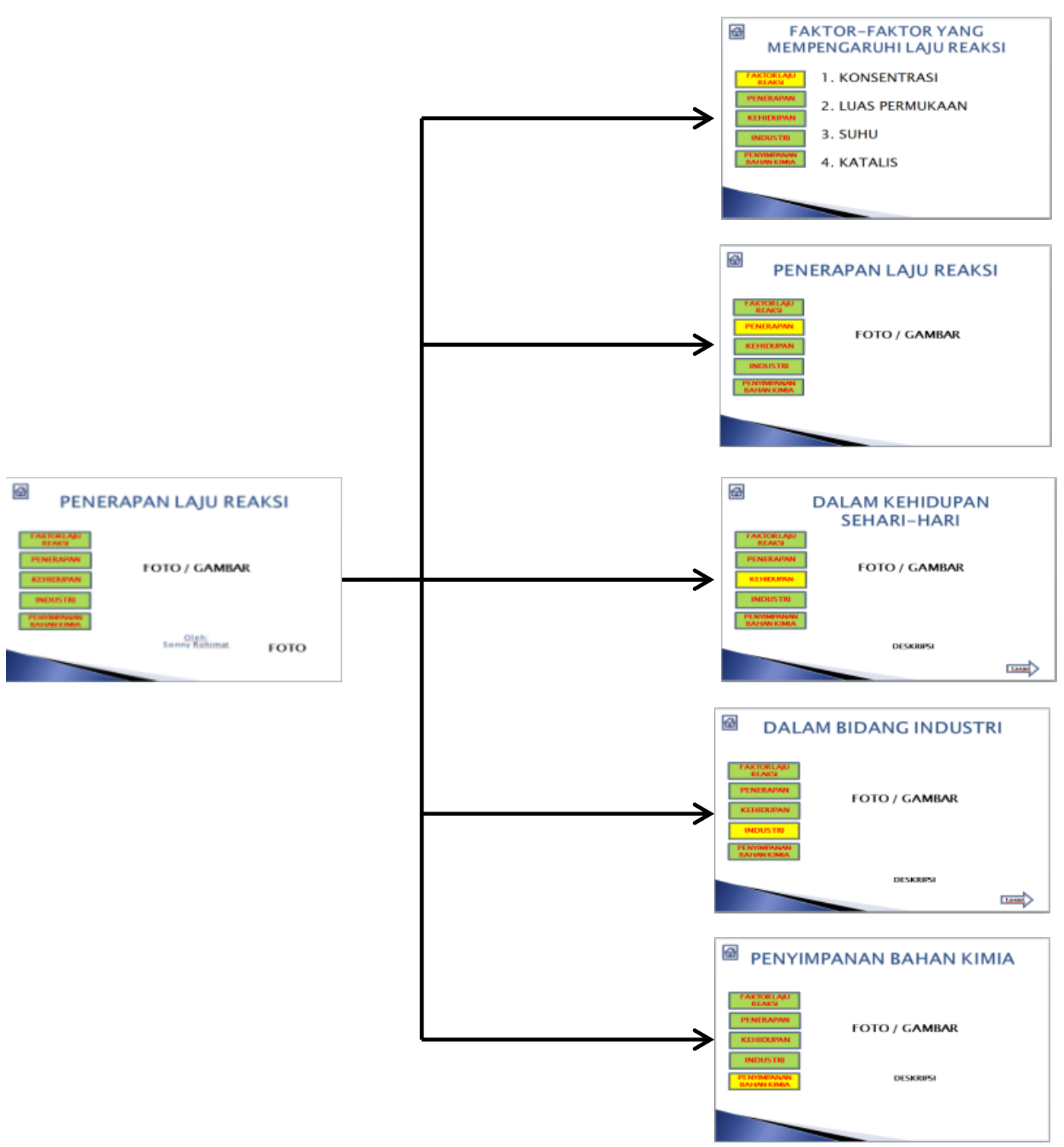

\section{Gambar 1. Desain Media Pembelajaran}

Kegiatan selanjutnya yang dilakukan pada tahap pertama adalah pembuatan media pembelajaran sesuai dengan desain yang telah dibuat. Media pembelajaran dibuat menggunakan slide master pada aplikasi Microsoft Power Point 2010. Proses pembuatan media pembelajaran ini dilakukan dengan empat langkah yaitu pesiapan, pembuatan slide master, pengisian slide master, dan penyimpanan file. Media pembelajaran yang dihasilkan berupa slide interaktif dalam format PowerPoint Presentation dan PoerPoint Show. Tampilan keseluruhan slide disajikan pada Gambar 2. 

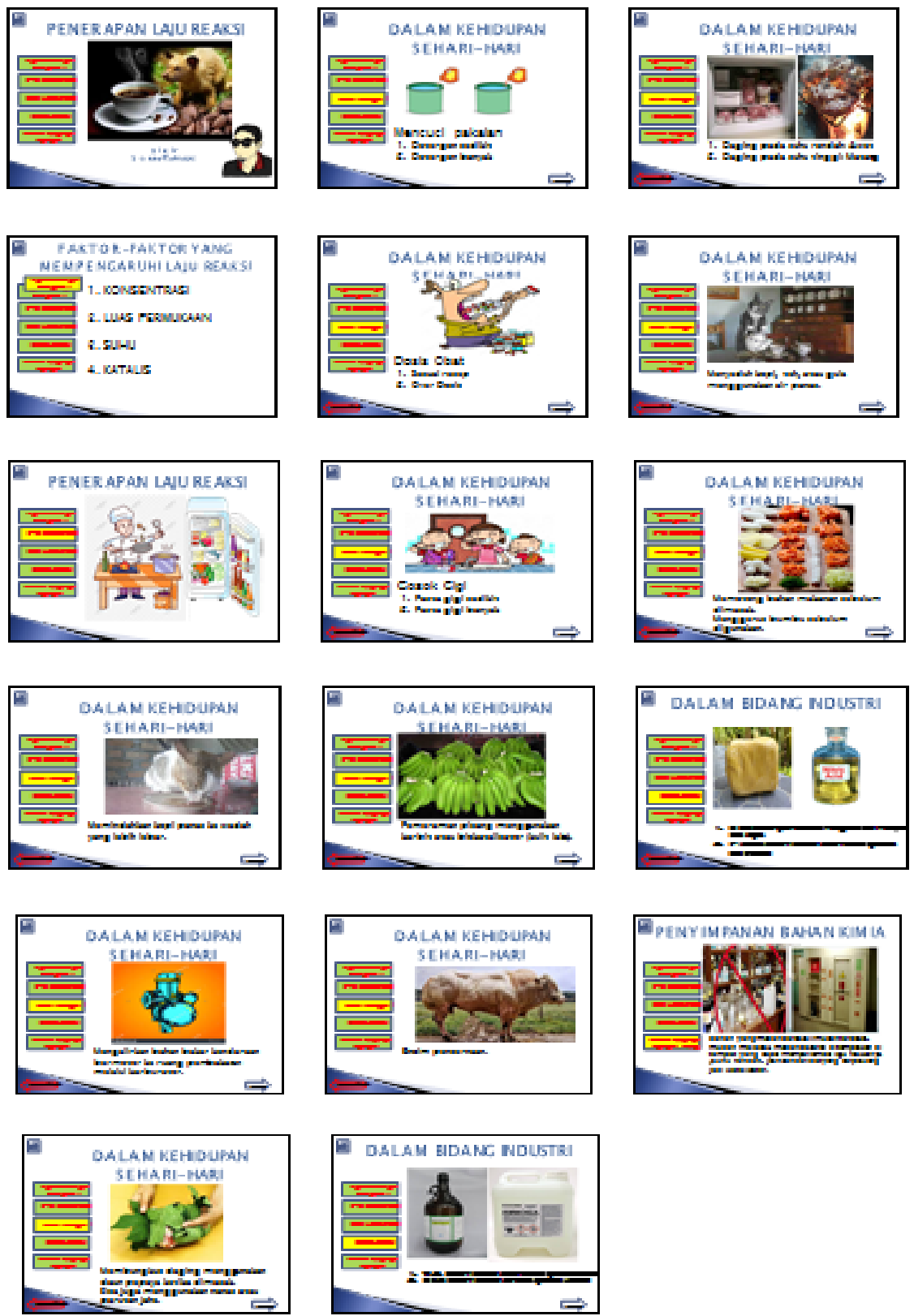

\section{Gambar 2. Tampilan Seluruh Slide Media Pembelajaran}

Tahap kedua pada penelitian ini adalah pelaksanaan pembelajaran kimia dengan memanfaatkan media pembelajaran yang telah dibuat. Pembelajaran dilakukan menggunakan model discovery learning. Pemanfaatan media pembelajaran tersebut dalam kegiatan pembelajaran disajikan pada Gambar 3.

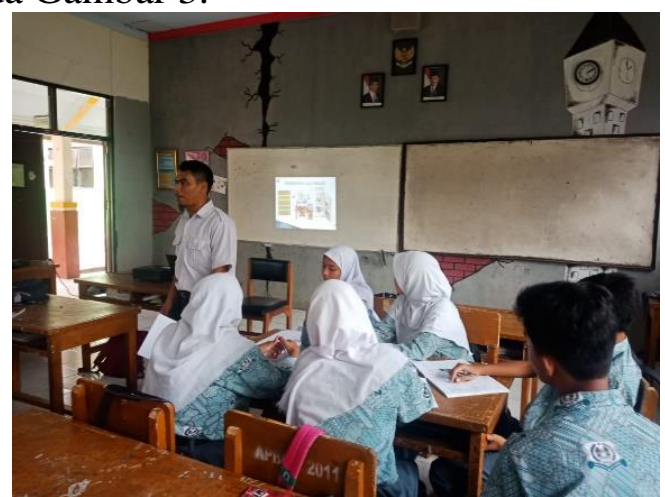

Gambar 3 Kegiatan Pembelajaran 


\section{Pembahasan}

Berdasarkan desain yang telah dibuat, media pembelajaran terdiri dari satu halaman beranda dan lima subjudul materi. Masing-masing subjudul materi terdiri dari satu slide atau lebih. Pemilihan subjudul materi ini disesuaikan dengan penjabaran materi Penerapan Laju Reaksi pada KD 4.6. yaitu Menyajikan hasil penelusuran informasi cara-cara pengaturan dan penyimpanan bahan untuk mencegah perubahan fisika dan kimia yang tak terkendali (Sutresna, Sholehudin, \& Herlina : 2016). Rincian dari masing-masing halaman beranda dan subjudul adalah sebagai berikut:

1. Halaman Beranda

Halaman beranda merupakan tampilan awal saat media pembelajaran dibuka. Halaman ini berisi judul materi yang dibahas, foto yang relevan dan menarik, nama dan foto penyusun, serta tombol-tombol menuju subjudul materi. Setiap tombol yang dipilih akan berubah warna dan masuk ke halaman sesuai subjudulnya.

2. Subjudul Faktor Laju Reaksi

Halaman subjudul Faktor Laju Reaksi berisi tentang faktor-faktor yang dapat mempengaruhi laju reaksi. Halaman ini digunakan untuk melakukan apersepsi terhadap materi pembelajaran sebelumnya yang berhubungan dengan materi yang akan dipelajari.

3. Subjudul Penerapan

Subjudul penerapan menampilkan subjudul materi dan sebuah gambar menarik yang dapat memberikan stimulus kepada para siswa tentang materi yang akan dibahas.

4. Subjudul Kehidupan

Subjudul kehidupan berisi sebelas slide yang menampilkan deskripsi dan gambar tentang penerapan laju reaksi dalam kehidupan sehari-hari.

5. Subjudul Industri

Subjudul industri berisi dua slide yang menampilkan deskripsi dan gambar tentang penerapan laju reaksi dalam bidang industri.

6. Subjudul Penyimpanan Bahan Kimia

Subjudul penyimpanan bahan kimia berisi satu slide yang menampilkan deskripsi dan gambar tentang penerapan laju reaksi dalam penyimpanan bahan-bahan kimia.

Adapun pada proses pembuatan media pembelajaran, langkah pertama yang dilakukan persiapan. Kegiatan yang dilakukan dalam persiapan pembuatan media pembelajaran ini adalah memastikan aplikasi Microsoft Power Point terpasang di komputer, menyiapkan konten pembelajaran, serta menyiapkan gambar dan foto yang akan digunakan. Konten pembelajaran berupa penjelasan materi Penerapan Laju Reaksi. Adapun gambar dan foto diambil dari laman internet yang berhubungan dengan penerapan laju reaksi.

Langkah kedua adalah pembuatan slide master. Slide master terletak pada menu View. Pada slide master ini dimasukkan background, kolom judul slide, dan konten yang harus muncul di semua slide. Sesuai dengan rancangan, maka pada slide master ini hanya ada tombol Home dan lima buah tombol menuju subjudul. Masing-masing tombol subjudul diberi latar warna hijau dan tulisan warna merah. Tampilan slide master disajikan pada Gambar 4.

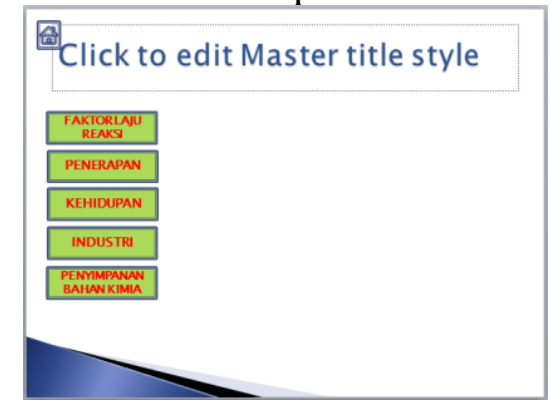

Gambar 4. Slide Mater

Langkah ketiga yang merupakan langkah paling penting dalam pembuatan media pembelajaran adalah pengisian slide. Isi slide bisa berupa konten materi, foto, gambar, 


\section{STRATEGY : Jurnal Inovasi Strategi dan Model Pembelajaran Vol 1. No 1. Juli Tahun 2021 e-ISSN : 2798-5466 P-ISSN : 2798-5725}

animasi, dan hyperlink (Amrina et al : 2019). Pada media pembelajaran ini pun slide diisi dengan judul, penjelasan singkat materi, gambar atau foto. Pada setiap slide dituliskan judul pada kolom yang tersedia di bagian tengah atas sesuai slide master yang telah dibuat. Jika slide mengandung gambar atau foto, maka gambar atau foto disalin (copy) dari computer lalu ditempel (paste) di slide tujuan. Cara lain yang untuk menyisipkan gambar atau foto adalah dengan memilih Picture pada menu Insert. Ukuran dan letak foto bisa diatur di masing-masing slide. Jika slide mengandung tulisan atau deskripsi, maka bisa menggunakan Text Box yang terletak pada menu Insert. Bentuk, ukuran, warna, dan efek huruf bisa diatur di masingmasing slide.

Isian lain pada slide adalah tombol subjudul aktif, hyperlink, serta tombol lanjut (next) dan kembali (previous). Subjudul aktif adalah subjudul yang slidenya sedang terbuka (aktif). Masing-masing satu tombol disalin dari slide master lalu diletakkan di slide pertama masingmasing subjudul. Selanjutnya warna tombol (hijau) diubah menjadi kuning menyala. Halaman beranda tidak menggunakan tombol subjudul tetapi menggunakan tombol Home yang sudah diatur melalui slide master. Setiap tombol aktif disisipi hyperlink atau tautan ke slide pertama tiap subjudul. Hyperlink ini dapat digunakan agar tombol yang dibuat tampak lebih hidup (Surachman : 2016). Caranya dengan mengaktifkan tombol yang akan digunakan lalu memilih hyperlink, pada menu Insert. Selanjutnya memilih halaman yang dituju sesuai dengan subjudul yang dipilih. Selain itu, Jika subjudul yang memiliki lebih dari satu halaman maka disisipkan tombol next (tanda panah ke kanan) di bagian kanan bawah atau prev (tanda panah ke kiri) di bagian kiri bawah. Di halaman pertama hanya ada tombol next, di halaman terakhir hanya ada tombol prev, dan di halaman lainnya ada tombol next dan prev. Pada tombol next dibuatkan hyperlink dengan memilih Next Slide, sedangkan pada tombol prev dibuatkan hyperlink dengan memilih Previous Slide.

Hal lain yang dilakukan dalam pengisian slide adalah mengatur animasi dan mengunci papan ketik (keyboard). Animasi digunakan untuk memberikan efek tertentu pada slide show, termasuk efek suara, baik ketika masuk, keluar, atau memberikan tekanan (emphasis). Animasi diberikan sesuai kebutuhan, sederhana, tapi menarik. Animasi bisa diatur permulaannya, durasinya, dan juga penundaannya. Animasi dapat diatur pada menu Animation. Penguncian keyboard dilakukan agar keyboard tidak aktif ketika sedang presentasi (Isroqmi : 2015). Dengan demikian, bagian yang aktif pada slide hanya tomboltombol yang mengandung hyperlink seperti tombol home, tombol subjudul, tombol next, dan tombol prev. Penguncian keyboard dilakukan melalui Set Up Slide Show pada menu Slide Show. Selanjutnya adalah memilih pengaturan Browsed at kiosk (full screen). Setelah memilih OK, maka keyboard akan terkunci ketika slide show diaktifkan (Isroqmi, 2015).

Langkah terakhir dalam proses pembuatan media pembelajaran ini adalah penyimpanan file yang sudah dibuat. Penyimpanan dilakukan dengan memilih Save As pada menu File. Selain menuliskan nama file, format file juga bisa diatur sesuai kebutuhan. Untuk kebutuhan presentasi tanpa ada pengeditan, format yang bisa dipilih adalah PowerPoint Slide Show (.ppsx). Akan tetapi jika file masih memerlukan perbaikan bisa dipilih format PowerPoint Presentation (pptx). Media pembelajaran yang telah dibuat kemudian dimanfaatkan pada proses pembelajaran. Untuk mendukung penggunaan media pembelajaran ini maka dipesiapkan bebagai peralatan yang dibutuhkan. Peralatan yang dimaksud adalah laptop, LCD projector, kabel, serta kontak dan instalasi listrik. Semua peralatan dipersiapkan dengan baik untuk meminimalisasi kendala teknis pada saat pembelajaran berlangsung.

Sesuai dengan model yang digunakan, yaitu discovery learning, langkah pembelajaran dilakukan dengan menggunakan enam sintaks. Keenam sintaks tersebut adalah pemberian rangsangan, identifikasi masalah, pengumpulan data, pengolahan data, pembuktian, dan penarikan kesimpulan (Devi, 2016). Selain media pembelajaran, dalam proses pembelajaran peserta didik juga diberikan Lembar Kerja Peserta Didik (LKPD) untuk masing-masing kelompok. Adapun penjelasan dari masing-masing sintaks yang dilakukan adalah sebagai berikut. 


\section{STRATEGY : Jurnal Inovasi Strategi dan Model Pembelajaran Vol 1. No 1. Juli Tahun 2021 e-ISSN : 2798-5466 P-ISSN : 2798-5725}

1. Sintak pemberian rangsangan, peserta didik mengamati gambar yang ditampilkan pada layar.

2. Sintak identifikasi masalah, peserta didik mengidentifikasi berbagai pertanyaan yang berkaitan dengan gambar yang ditampilkan.

3. Sintak pengumpulan data, peserta didik mencari informasi dari berbagai sumber belajar, termasuk buku paket.

4. Sintak pengolahan data, peserta didik melakukan diskusi kelompok untuk menyelesaikan LKPD.

5. Sintak pembuktian, masing-masing perwakilan kelompok menyampaikan hasil kerjanya serta saling menanggapi dengan kelompok lain. Guru mengarahkan proses pembuktian ini agar sesuai dengan konsep.

6. Sintak penarikan kesimpulan, peserta didik menyimpulkan penerapan laju reaksi dalam kehidupan sehari-hari, industri, dan penyimpanan bahan kimia.

Proses kegiatan pembelajaran berlangsung dengan baik. Peserta didik mengikuti seluruh proses pembelajaran dengan antusias. Hal ini terlihat dari keseriusan peserta didik dalam memperhatikan penjelasan guru, keaktifan dalam bertanya, melakukan diskusi dan menyelesaikan LKPD, serta menyampaikan dan menanggapi hasil diskusi kelompok. Seluruh kelompok menyelesaikan LKPD dengan baik dan saling melengkapi satu sama lain.

Penggunaan media pembelajaran berupa PowerPoint Show (pptx) yang menggunakan slide master juga berlangsung dengan baik. Seluruh tampilan slide show berjalan sesuai dengan desain yang telah dibuat. Selain itu, peserta didik juga tampak tertarik dengan slide yang ditayangkan karena terlihat interaktif dan tidak monoton. Pemilihan gambar yang cukup unik dan lucu tapi sesuai materi pembelajaran juga membuat siswa lebih tertarik dalam mengikuti pembelajaran. Hal ini terlihat dari tanggapan peserta didik setiap kali pergantian slide.

\section{KESIMPULAN}

Media pembelajaran dengan memanfaatkan fitur slide master pada aplikasi Microsoft Power Point bisa dibuat untuk materi Penerapan Laju Reaksi. Dengan memanfaatkan slide master, media pembelajaran menjadi lebih menarik dan interaktif. Dengan demikian, peserta didik pun lebih tertarik mengikuti pembelajaran. Hal ini didukung dengan model discovery learning yang mendorong peserta didik melakukan penemuan secara kolaboratif. Pemanfaatan slide master pada aplikasi Microsoft Power Point bisa digunakan untuk berbagai materi atau kompetensi dasar yang lain baik pada mata pelajaran kimia ataupun mata pelajaran yang lain.

\section{DAFTAR PUSTAKA}

Amanah, S. (2016). Pedagogi: Media Pembelajaran Kimia - SMA. Bandung: PPPPTK IPA.

Amrina, D. E., Jaenudin, R., Fatimah, S., \& Mardetini, E. (2019). Pelatihan Media Powerpoint Slide Master Berbasis Pembelajaran Kolaboratif di SMA Kelurahan Bukit Lama Palembang. Jurnal Pemberdayaan Masyarakat Madani (JPMM), 3(1), 1-18, from https://doi.org/10.21009/JPMM.003.01.01 .

Anisa, F., \& Yuliyanto, E. (2017). Analisis Faktor yang Mempengaruhi Pembelajaran Kimia di SMA Teuku Umar Semarang. In PROSIDING SEMINAR NASIONAL \& INTERNASIONAL. Retrieved from http://103.97.100.145/index.php/psn12012010/article/view/3138/3035

Devi, P.K. (2016). Pedagogik: Model-Model Pembelajaran IPA dan Implementasinya. Bandung: PPPPTK IPA.

Inayah, L., \& Astuti, A. P. (2017). Analisis Tingkat Keberhasilan Pembelajaran Laboratorium dalam Pelajaran Kimia di SMA Negeri 9 Semarang. In PROSIDING SEMINAR 
NASIONAL \& INTERNASIONAL. Retrieved from http://103.97.100.145/index.php/psn12012010/article/view/3060/2969.

Isroqmi, A. (2015). Pemilihan Software Aplikasi Untuk Pembuatan Media Pembelajaran Interaktif (Studi Kasus: Aplikasi PowerPoint). Jurnal Dosen Universitas PGRI Palembang. From https://jurnal.univpgri-palembang.ac.id/index.php/prosiding/article/view/377/270.

Pangestika, R. R., Wijayati, N., \& Widodo, A. T. (2017). Peningkatan Hasil Belajar Siswa Melalui Pendekatan Joyful Learning Pada Pembelajaran Kimia. Jurnal Inovasi Pendidikan Kimia, 11(1), from https://journal.unnes.ac.id/nju/index.php/JIPK/article/view/9713/6230.

Surachman, E. (2016). Workshop Pemanfaatan Media Pembelajaran Sebagai Upaya Peningkatkan Efektifitas Pembelajaran serta Profesionalitas Pendidik di SMP Negeri 194 Jakarta. Sarwahita, 13(2), 111-119, from https://doi.org/10.21009/sarwahita.132.06.

Sidiq, U. \& Choiri, M.M. (2019). Metode Penelitian Kualitatif di Bidang Pendidikan. Ponorogo: Nata Karya.

Siyoto, S. \& Sodik, M.M. (2015). Dasar Metodologi Penelitian. Sleman: Literasi Media Publishing.

Sutresna, N., Sholehudin, D. \& Herlina, T. (2016). Aktif dan Kreatif Belajar Kimia 2. Bandung: Grafindo Media Pratama. 